\title{
The effect of using ribbed absorber plates on enhancing the heat transfer of solar chimneys
}

\author{
Mohammed N. Jihad ${ }^{1}$, Nabil J. Yasin ${ }^{2}$, Kadhum A. Jehhef ${ }^{3}$ \\ ${ }^{1}$ Master's Research Scholar, Thermal engineer department Technical Engineering College - \\ Baghdad. Middle Technical University, Baghdad, Iraq \\ ${ }^{2}$ Prof. Technical Engineering College - Baghdad, Middle Technical University, Baghdad, \\ Iraq \\ ${ }^{3}$ Power Mechanics Department, Institute of Technology, Middle Technical University, \\ Baghdad, Iraq \\ 1'mohammed87nabel@gmail.com, ․ㅡabiljamil58@gmail.com, ${ }^{3}$ kadhumaudaa@gmail.com
}

\begin{abstract}
Under different geometrical features and in Iraqi environmental circumstances, a numerical and experimental investigation of a solar chimney was carried out the study that dealt with an important aspect, which is to increase the surface area of the absorbent plate while maintaining the outer dimensions and limits by using three model of absorber surface (flat plate, Triangular $V$ grooved corrugated plate and trapezoidal corrugated absorber plate). the work was carried out using a single vertical solar chimney of a single room has a volume $27 \mathrm{~m}^{3}$ modeling $1 \mathrm{~m}^{3}$ placed on the southern wall of wooden chamber having a size of $(1 \times 1 \times 1) \mathrm{m}$ and absorber plate $(0.9 \times 0.99) \mathrm{m}$. In addition to studying the effect of the air gap width $(0.1,0.2) \mathrm{m}$ on the test model with all absorber plate are used at different inclination angles inward $\left(0^{\circ}, 5^{\circ}, 10^{\circ}\right.$ and $\left.15^{\circ}\right)$ the test model. All variable was taken with varying solar radiation intensity $(150,250,350,450,550$ and 700$) \mathrm{W} / \mathrm{m}^{2}$ along the day time. Numerical simulation of the test models using the Ansys Fluent program V18.1 to solve the governing continuity, momentum and energy equations with a standard $(k-\varepsilon)$ standard turbulence model associated with laws of the wall along solid boundaries were solved numerically, Experimental and Theoretical results of the present study show that the optimum model of the test absorber plates with air gap width and inclination angle according to Air change per hour (ACH) calculation is Triangular V-grooved absorber plate with air gap width $0.2 \mathrm{~m}$ and inclination angle $10^{\circ}$. For this inclination angle and air gap width at $1700 \mathrm{~W} / \mathrm{m}^{2}$ the $\mathrm{ACH}$ is about $10 \%$ higher than modell (flat absorber plate) and more than model3(trapezoidal plate) by $17 \%$.
\end{abstract}

Keywords: ACH Air change per hour, ASHRE American Society of Heating, Refrigerating, and Air Conditioning Engineers, CFD Computational Fluid Dynamic, SC Solar chimney, GE Governing equations, Gr Grashof number, Nu Nusselt number, Ra Rayleigh number

\section{INTRODUCTION}

One of the recent technologies used by renewables to save energy and reduce excessive usage (solar energy). In building, natural ventilation utilizing a solar chimney was one of the simplest ways to save energy. Several research and inquiries have been conducted to determine the use of free clean energy (like solar radiation) in the division of clean energy Ventilation and evaporative cooling modes for ventilation. The aim from that to Decreasing the tremendous use of energy. Use this free and renewable energy to This implies the need to minimize emissions, which means the global need to reduce Potential warming. All of these study findings are dealing with the control of to compensate for the reduction in energy by storing it and then releasing it, Power in the absence of an energy source. The literature reviews include three types of reviews: statistical and computational research, experimental tests, numerical studies and experiments[1]. Literature scanning of the previous work of 
the researcher shows that the best way to ventilate the passive building is to ventilate the solar chimney, decreasing the room temperature and further reducing the ventilation load of traditional air conditioning for cooling purposes. Several tests and experimental work were conducted to enhance the passive cooling and ventilation system performance.

M. Maerefat and A.P. Haghighi, (2009)[2] studied usage of solar chimneys (SC) along with earth to air heat exchangers (EAHE) is currently being researched An interconnected system of a few solar chimneys with one or two at most (EAHE) cooling pipe is found to be capable of Provide the requirement for indoor thermal comfort, so the temperature 28.15 to $31.94{ }^{\circ} \mathrm{C}$, which is beyond the appropriate range, is maintained. According to Bureau of Indian Standards (BIS) [3] with 3 to $7 \mathrm{ACH}$, which guarantees the required level of ventilation. As can be seen in the case of higher cooling needs longer More cooling pipes from the EAHE are required. Khanal, C. Lei, (2015)[4] performed A numerical analysis of the buoyancy caused by turbulent air flow in a Solar chimney with inclined passive wall (IPWSC) from $0^{\circ}$ to $6^{\circ}$ attached to a room (ventilated space) at constant heat flux 500 $\mathrm{w} / \mathrm{m}^{2}$ it is found that the optimal angle of inclination is $4^{\circ}$, that is impartial of the Rayleigh number. Bhardwaj (2017) [5] Present analysis, the air changes are per Hour (ACH) and air output velocity are configured for vertical solar output chimney connected to a $1 \mathrm{~m} \times 1 \mathrm{~m} \times 1 \mathrm{~m}$ room by using ANSYS software 3D module with four windows to wall ratio (WWR). 0.2, 0.3, 0.4 and $0.5 \mathrm{~m}$ the chimney air gap varied from $0.1 \mathrm{~m}$ to $0.4 \mathrm{~m}$ with increment of $0.1 \mathrm{~m}$. window of size $0.5 \mathrm{~m} \times 0.4 \mathrm{~m}$ is most suitable for both higher air changes per hour and air exit velocity with east orientation of window. The air gap of $0.2 \mathrm{~m}$ provide maximum $\mathrm{ACH}$ where the air gap of $0.1 \mathrm{~m}$ provide higher air velocity in the present study. Mohammad H. Naraghi (2015) [6] presented a time-dependent study of solar chimneys. The equations for energy balance with respect to three components of solar chimneys, absorbing layer, cover glass and air space, discretized are use an implicit finite difference method to time. The discretized time - varying equations for energy balance using the Newton-Raphson process, various time measures over a 24-h duration are overcome. It has been shown that there is an increase in the heat capacity of the absorption plate results in a higher degree of airflow during morning hours, whether there is no solar radiance or faint in the night. The thermal mass of the absorbing plate is increased resulting in less difference in the rate of airflow. Many of the absorption characteristics the metal can be used to maximize its heat mass which has a steady 24-hour. Karim, at. el (2004)[7] experimental study of three plate types, flat plate, finned and v-corrugated plate. to achieve an optimal setup for a Sun dryer, based on ASHRAE normal climatic conditions. The performance of the three collectors is evaluated through a range of nature events and environments. Using in draying process connected with axial fan the test done in single and double pass. The most successful V-corrugated collector and flat plate. Under effective collector. Results led to that the V-corrugated collector is 7$12 \%$ more powerful than the flat Collectors tray. Double-pass operation increases collector efficiency in the flat plate collector, V-grooved plate. Mathur et al (2006)[8] was designed A cubical wooden chamber having a size of $(1 \mathrm{~m} \times 1 \mathrm{~m} \times 1) \mathrm{m}$ was made. One of its vertical sides was made like a vertically sliding shutter and he studied the variables that occur on the solar chimney, including the height of the chimney, as well as inlet height and the air gup between the absorbent surface and the glass. Show that the rate of ventilation increases with increase of the ratio between height of absorber and gap between glass and absorber. Khanal \& Lei (2014)[9] performed the experiments with an inclined passive wall solar chimney (IPWSC) model using a uniform heat flux on the active layers (absorptive) Wall. In this design, inclination angles of the passive wall in the range of $0-6^{\circ}$.and the room similarity $(0.8 \times 0.7 \times 0.5) \mathrm{m}$ and the absorber plate is aluminum thickness $0.003 \mathrm{~m}(0.5 \times 0.7) \mathrm{m}$ with variable air gup. Flow velocity is found to be strongly affected by the slope of the passive wall the maximum flow velocity at a $6^{\circ}$ about $0.1 \mathrm{~m}$ air gup. while the inclination angle has no effect on temperature distribution. Bassiouny (2008)[10] The study takes in account some geometrical parameters such as chimney inlet size and air gap width of the solar chimney attached to the room (1x1x1) m. the chimney width has a more significant effect on ACH compared to the chimney inlet size. The results showed that the absorber average temperature could be correlated to the intensity as: $\left(\mathrm{T}_{\mathrm{w}}=3.51 \mathrm{I}^{0.461}\right)$ with an accepted range of approximation error. Imran, et al. (2015)[11] describe the efficiency of a solar chimney under different geome- tric features. Two dimensional, steady by natural convection within an inclined solar chimney, turbulent flow was created. This flow has been Nu. and Ex. evaluated at angles of inclination $15^{\circ}$ to $60^{\circ}$. solar heat flux $150-750 \mathrm{~W} / \mathrm{m}^{2}$ and chimney $(0.05,0.1$ 
and 0.15$) \mathrm{m}$ high. The Nu. and Ex. model findings the angle of inclination of the chimney was $60^{\circ}$ to achieve the full ventilation volume. The rate of ventilation at this angle of inclination was around $20 \%$ more than $45^{\circ}$. Highest rate of ventilation induced was found to be ACH in a room of $12 \mathrm{~m}^{3}$ volume, at solar radiation $750 \mathrm{~W} / \mathrm{m}^{2}$ on inclined surface $60 \mathrm{o}$ with aspect ratio of 13.3 for $2 \mathrm{~m}$ length of solar chimney. Abdeen, et al. (2019)[12] It performed the buildings ventilated with the aid of passive solar chimneys. A (CFD) model" was estimated. The Renormalization Group "k- $\varepsilon$ (RNG) turbulence model" The experimental work is achieved using a solar chimney of $1.85 \mathrm{~m}$ height, $2.65 \mathrm{~m}$ width, $75^{\circ}$ inclination angle, and $0.28 \mathrm{~m}$ air gap. At mean solar radiation values of 500,700 , and $850 \mathrm{~W} / \mathrm{m} 2$, the current solar chimney passively generates air velocity of up to $0.28,0.47$, and $0.52 \mathrm{~m} / \mathrm{s}$, respectively. By eliminating sensible and latent heat from the body, these increased air velocities ma improve thermal comfort upper limits.

\section{EXPERIMENTAL SET UP}

The aim of the present experiments was to investigate the influence of several parameters on the efficiency of the solar chimney in steady-state conditions, as well as to validate the numerical results with the experimental data. These parameters are illustrated as (the air gap between the absorber plate and the transparent glass cover, inclination angle of the absorber plate, and the solar radiation intensity with three types of absorber plate (flat absorber plate, triangular V-grooved corrugated absorber plate and trapezoidal corrugated absorber plate). The experimental study was conducted in Baghdad city at $33.3^{\circ}$ latitude north and $44.2^{\circ}$ longitude east. The chimney was installed vertically of the test room and oriented at the direction of the south with inclination angles of $\left(0^{\circ}, 5^{\circ}, 10^{\circ}, 15^{\circ}\right)$ inward of testing room (1x1x1) as shown in Figure 1. The experimental rig is portrayed schematically in photographically in Figure 2. The mechanism is made up of two main parts the solar chimney and the room configuration. the solar chimney is containing from absorber plat have three models painted with black mat (flat, $\mathrm{V}$-grooved and trapezoidal). The absorber plate was $(0.9 \mathrm{~m}$ length, $0.99 \mathrm{~m}$ width and $0.001 \mathrm{~m}$ thickness). The properties of the absorber plate are absorptivity $(\alpha)$ and reflectivity $(\rho)$ equal to $(0.9)$ and $(0.1)$, respectively[13]. The flat plate length is $0.9 \mathrm{~m}$ but the trapezoidal absorber plates the length is $1.52 \mathrm{~m}$ corrugated to the characteristic length $0.9 \mathrm{~m}$ and the triangular V-grooved absorber plate is about $1.24 \mathrm{~m}$ corrugated to the characteristic length $0.9 \mathrm{~m}$ also Figure 3 . The properties of the glass are the transmissivity $(\tau)$ equal to 0.84 for clear glass. The reflectivity $(\rho)$, proportion of incident sun light reflected, is equal to 0.1.The final property is the absorptivity $(\alpha)$, proportion of incident sun light absorbed within the material, is equal to (0.06)[13]. In the test model 10 Thermocouples type $(\mathrm{k})$ install the positioned at selected locations. As shown in Figure 4 thermocouples (T1) is fixed on the inlet suction, (T2, T3, T4, T5 and T6) is install in vertical middle of the room to measuring the distributions air temperature. (T7, T8, T9) install on the absorber plate with thermal insulator behind it to prevent the effect of environment conditions on the thermocouple's readings. The temperature of air outlet measured by thermocouple (T10, T11) and. The ambient temperature was measured by thermometer and from Standard climate of Baghdad city. The thermocouples were used for the measurement of temperature were connected to digital data loggers BTM-4208SD with 12 channels manufactured by (LUTRON ELECTRONIC ENTERPRISE CO., LTD). Also used Fluke 62 MAX Infrared Thermometer. The air speed at the outlet of the solar chimney and at inlet opening of the room were measured by using hot-wire anemometer probe model (TES-1341). The hot-wire which is able to measure accurately very low air velocities having a resolution of $0.1 \mathrm{~m} / \mathrm{s}$, range of $(0-30) \mathrm{m} / \mathrm{s}$, and an accuracy as $\pm 3 \%$ of its reading. The solar radiation strength was measured using a TES-1333R solar power meter, which has a resolution of $0.1 \mathrm{~W} / \mathrm{m} 2$ and a precision of $5 \%$ of its reading. The experimental procedure for collection the period data was from February to May,2021 between 08:00 AM to 04:00PM. The data were recorded in the morning time for 24 case each model have 8 case. since the collector was fixed on the south facing direction, therefore less solar heat gain and then began to increase. The solar chimney was tested under four different angles $\left(0^{\circ}, 5^{\circ}, 10^{\circ}, 15^{\circ}\right)$ and two different gaps air gap width $(0.1,0.2) \mathrm{m}$. 


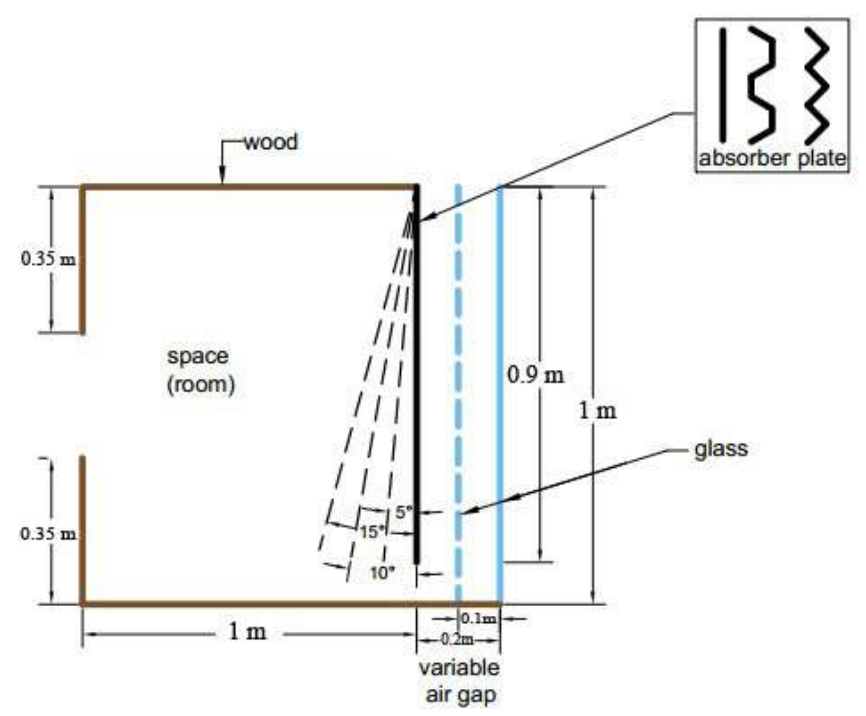

Figure1. Schematic diagram for experimental apparatus
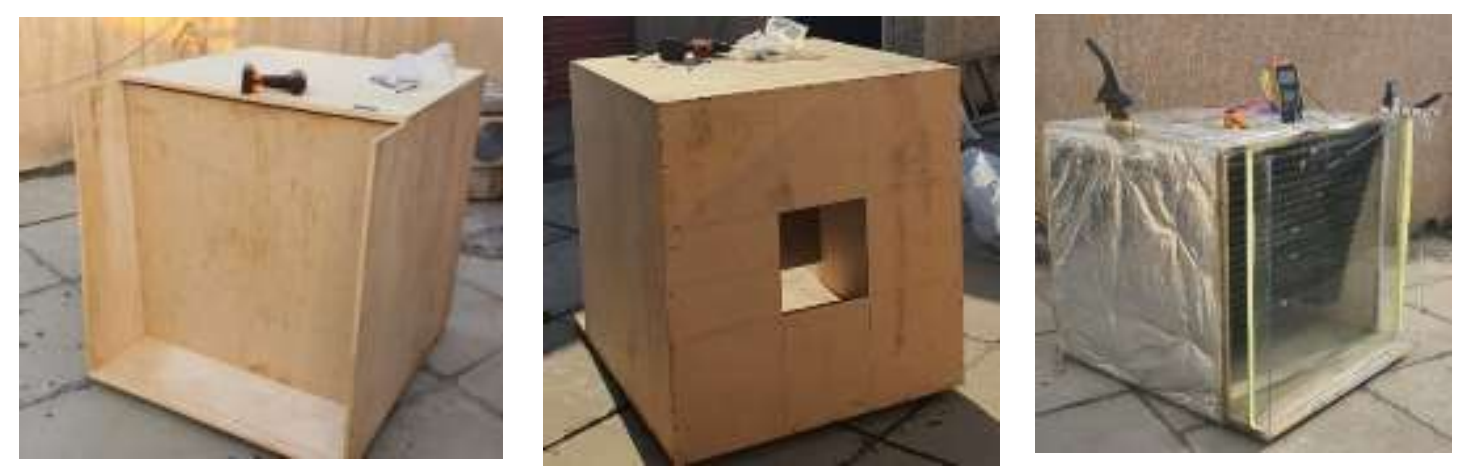

Figure 2. Photographic picture for experimental apparatus
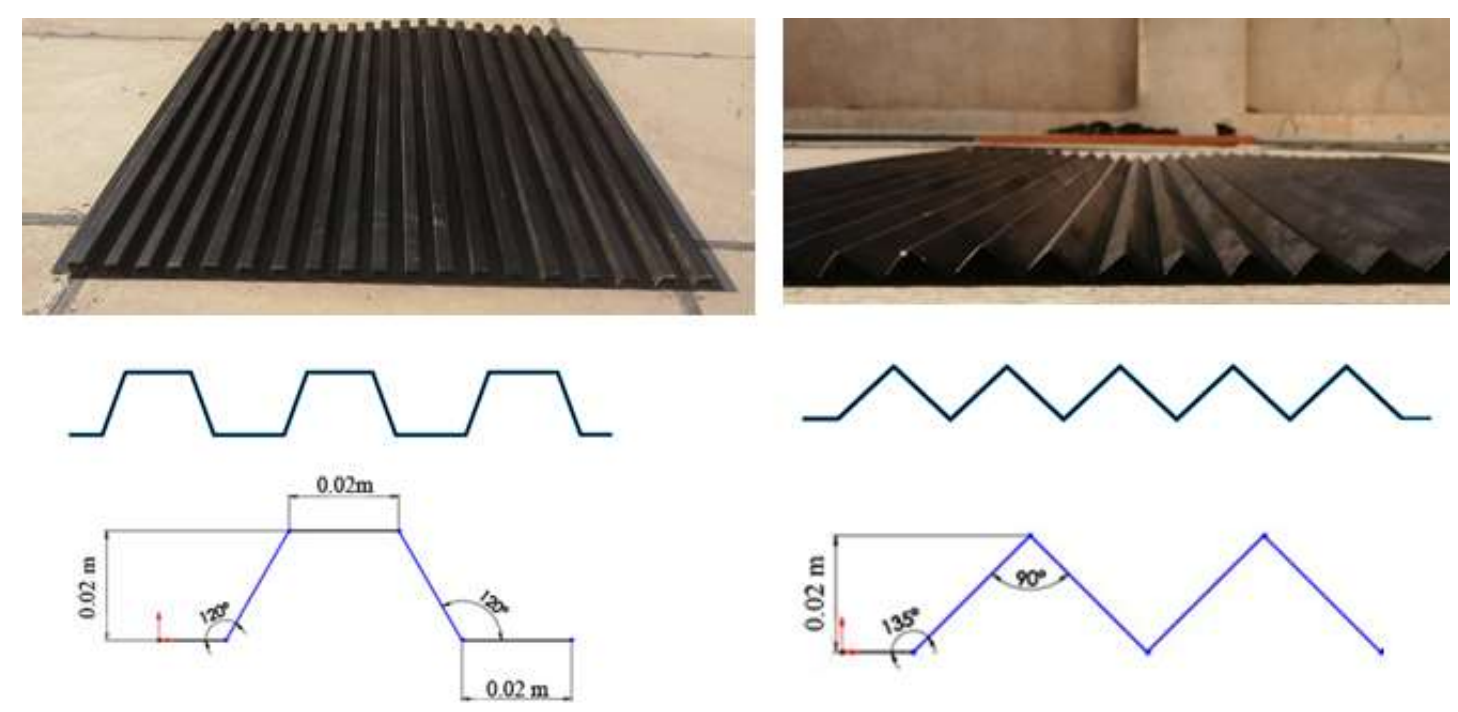

Figure 3. Absorber plate type used in experimental test model 


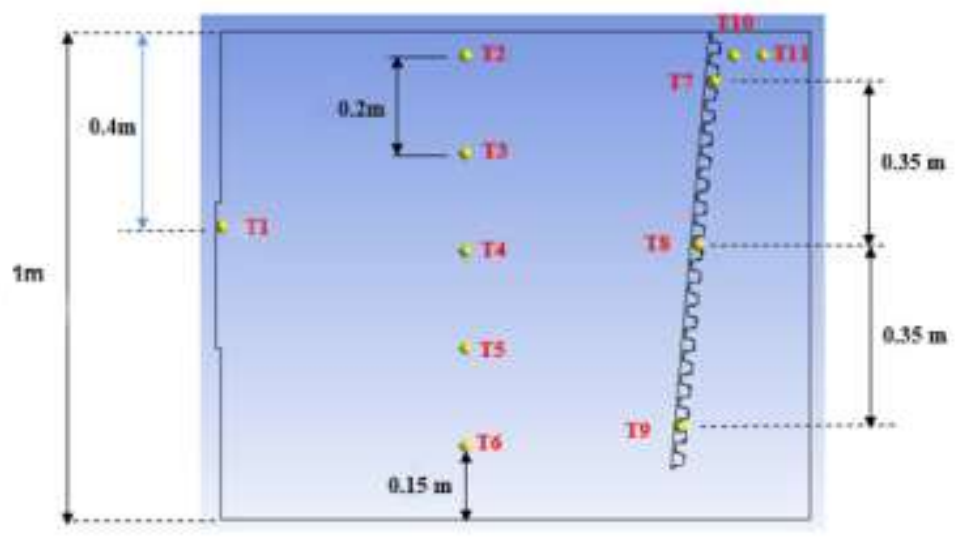

Figure 4. Schematic diagram for thermocouple temperature distribution

\section{MATHEMATICAL ANALYSIS}

\subsection{Mathematical Ventilation model of Solar Chimney}

Figure 5 demonstrates the physical model and boundary state for ventilation mode. More information for BC implemented in statistical models for vertical solar chimney and inclined absorber plate in order to analyzed the energy balance of main components, such as (glass, air stream within SC and absorber plate. Also, we show the mass balance of the air stream according to previous literature. Laminar and turbulent flows range are classified in the present study according to the Rayleigh number. The flow transition from laminar to turbulent is around Rayleigh number $\left(10^{9}\right)[14]$.

\section{Grashof number}

The modified Grashof number is a criterion of the ratio of buoyancy force to the viscous force[15]

$G r=\frac{g \beta \dot{q} L c^{4}}{v_{f}^{2} k_{f}}$

\section{Rayleigh number}

The Rayleigh number in the present study was( $1.412 * 10^{9}$ ), The Rayleigh number was $>10^{9}$ therefore the flow is turbulent

$\operatorname{Ra}=\boldsymbol{G r} * \boldsymbol{P r}$

\section{Nusselt's number}

The Nusselt's number is a function the both of the Rayleigh and Prandtl numbers, as given by the equation below [16]

$\mathrm{N}_{\mathrm{u}}=0.68+\frac{0.67 \mathrm{R}_{\mathrm{a}}^{0.25}}{\left[1+\left(\frac{0.494}{\mathrm{Pr}_{\mathrm{r}}}\right)^{9 / 16}\right]^{4 / 9}}$

Convective heat transfer coefficient[16]

$h=\frac{\mathrm{k}_{\mathrm{f}} \mathrm{N}_{\mathrm{u}}}{\mathrm{L}_{\mathrm{s}}}$

Because of its low temperature range, air physical characteristics can vary linearly with air temperature. Based on tabled data from Incropera and DeWitt[17] for air characteristics between $300 \mathrm{~K}$ and $350 \mathrm{~K}$, the following empirical relationships are proposed:

$\mu_{\mathrm{f}}=18.46 \times 10^{-6}+0.0472 \times 10^{-6} \times\left(T_{f}-300\right)$

$\mathrm{K}_{\mathrm{f}}=26.3 \times 10^{-3}+0.074 \times 10^{-3} \times\left(T_{f}-300\right)$ 


$$
\begin{aligned}
& \rho_{\mathrm{f}}=1.1614-3.53 \times 10^{-3} \times\left(T_{f}-300\right) \\
& \mathrm{C}_{\mathrm{p}}=\left[10.07+0.0004 *\left(T_{f}-27\right)\right] \times 100 \\
& v_{\mathrm{f}}=\frac{\mu_{\mathrm{f}}}{\rho_{\mathrm{f}}}
\end{aligned}
$$

\section{Air change per hour}

The air change per hour $(\mathrm{ACH})$ is a measurement used to evaluate the efficiency of a solar chimney. It is described as the ratio of the volume flow rate of air to the volume of the space. ACH is a common means of describing the rate of ventilation. This index can be determined using the ASHRAE equation below[18]

$$
\begin{aligned}
& \mathbf{A C H}=\frac{\mathrm{Q} \text { vent } \times 3600}{V_{\text {room }}} . \\
& \mathrm{Q}_{\text {vent }}=\mathrm{V}_{\text {exit }} * \mathrm{~A}_{\text {exit }}
\end{aligned}
$$

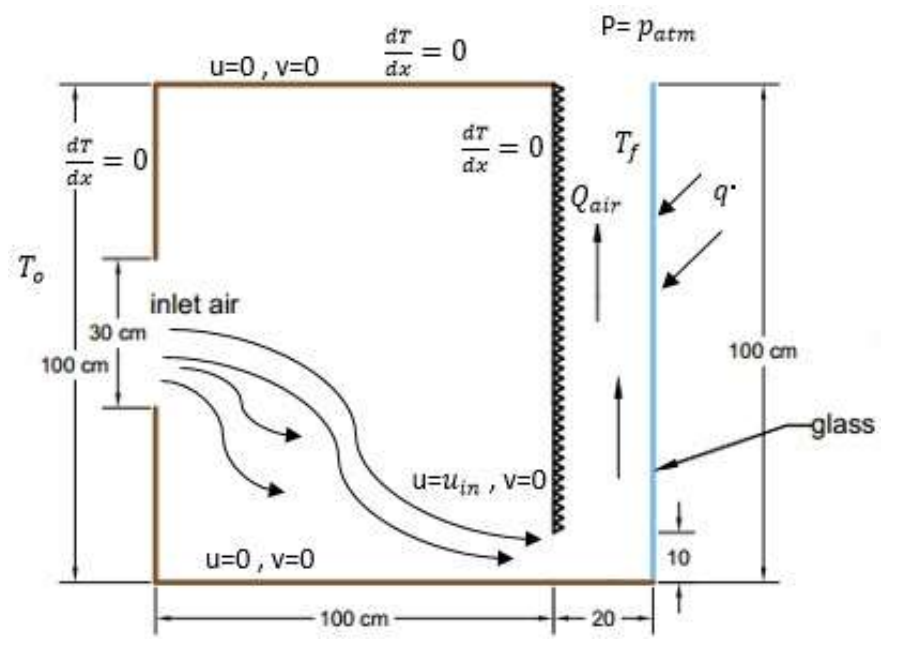

Figure 5. Description of the boundary condition of the physical model

\subsection{The Governing Equations}

The equations that describe the flow of a fluid and heat are the conservation of mass, momentum and energy equations. These equations describe plane, turbulent and incompressible flow, taking the following forms[14]

\section{- Conservation of Mass}

$\frac{\partial}{\partial x}(\rho \mathrm{u})+\frac{\partial}{\partial y}(\rho \mathrm{v})=0$

- Conservation of Momentum (Navier-Stokes equation):

- $\quad x$ - direction (u- momentum)

$$
\begin{gathered}
\frac{\partial \mathrm{uu}}{\partial x}+\frac{\partial v u}{\partial \mathrm{y}}=-\frac{1}{\rho} \frac{\partial \mathrm{p}}{\partial x}+\frac{1}{\rho} \frac{\partial}{\partial x}\left[\mu_{\text {eff }} \frac{\partial \mathrm{u}}{\partial x}\right]+\frac{1}{\rho} \frac{\partial}{\partial y}\left[\boldsymbol{\mu}_{\text {eff }} \frac{\partial \mathrm{u}}{\partial y}\right]+\boldsymbol{S}_{\boldsymbol{u}} \\
\bullet \quad \mathbf{y} \text { - direction (v-momentum) } \\
\frac{\partial v u}{\partial x}+\frac{\partial v v}{\partial \mathrm{y}}=-\frac{1}{\rho} \frac{\partial \mathrm{p}}{\partial y}+\frac{1}{\rho} \frac{\partial}{\partial x}\left[\mu_{e f f} \frac{\partial v}{\partial x}\right]+\frac{1}{\rho} \frac{\partial}{\partial y}\left[\mu_{\text {eff }} \frac{\partial v}{\partial y}\right]-\frac{2}{3} \frac{\partial \mathrm{k}}{\partial y}+S_{v}
\end{gathered}
$$

- Energy equation

$$
\frac{\partial u T}{\partial x}+\frac{\partial v T}{\partial y}=\frac{1}{\rho} \frac{\partial}{\partial x}\left[\Gamma_{e f f} \frac{\partial T}{\partial x}\right]+\frac{1}{\rho} \frac{\partial}{\partial y}\left[\Gamma_{e f f} \frac{\partial T}{\partial y}\right]
$$


- Turbulent kinetic energy

$\frac{\partial u k}{\partial x}+\frac{\partial v k}{\partial y}=\frac{1}{\rho} \frac{\partial}{\partial x}\left[\left(\mu+\frac{\mu_{t}}{\sigma_{k}}\right) \frac{\partial k}{\partial x}\right]+\frac{1}{\rho} \frac{\partial}{\partial y}\left[\left(\mu+\frac{\mu_{t}}{\sigma_{k}}\right) \frac{\partial k}{\partial y}\right]+\frac{1}{\rho}\left(\mathrm{G}_{k}+\mathrm{G}_{b}\right)-\varepsilon$

- Dissipation rate $(\varepsilon)$

$\frac{\partial u \varepsilon}{\partial x}+\frac{\partial v \varepsilon}{\partial y}=\frac{1}{\rho} \frac{\partial}{\partial x}\left[\left(\mu+\frac{\mu_{t}}{\sigma_{\varepsilon}}\right) \frac{\partial \varepsilon}{\partial x}\right]+\frac{1}{\rho} \frac{\partial}{\partial y}\left[\left(\mu+\frac{\mu_{t}}{\sigma_{\varepsilon}}\right) \frac{\partial \varepsilon}{\partial y}\right]+\mathrm{C}_{1} \frac{\varepsilon}{\rho \mathrm{k}}\left(\mathrm{G}_{k}+\mathrm{C}_{3} \mathrm{G}_{b}\right)-\mathrm{C}_{2} \frac{\varepsilon^{2}}{\mathrm{k}}$

Where:

$\boldsymbol{\mu}_{\boldsymbol{e f f}}$ Effective viscosity coefficient

$\mu_{\text {eff }}=\mu+\mu_{t}$

$\boldsymbol{\Gamma}_{\boldsymbol{e f f}}$ Effective diffusion coefficient

$\Gamma_{\text {eff }}=\frac{\mu}{\mathrm{p}_{r}}+\frac{\mu_{t}}{\sigma_{t}}$

$\boldsymbol{\mu}_{\boldsymbol{t}}$ Turbulent viscosity

$\mu_{t}=\rho C_{\mu} \frac{k^{2}}{\varepsilon}$

$S_{u}=-\frac{2}{3} \frac{\partial \mathrm{k}}{\partial x}$

$S_{v}=g \beta\left(T_{f}-T_{i n}\right)$

buoyancy in $x-$ direction $=\rho g \beta\left(T-T_{\text {in }}\right) \sin \theta$

buoyancy in $y-$ direction $=\rho g \beta\left(T-T_{\text {in }}\right) \cos \theta$

$\mathbf{G}_{\boldsymbol{k}}$ kinetic energy generation by shear

$\mathrm{G}_{k}=\mu_{t}\left(2\left[\left(\frac{\partial u}{\partial x}\right)^{2}+\left(\frac{\partial v}{\partial y}\right)^{2}\right]+\left(\frac{\partial u}{\partial y}+\frac{\partial v}{\partial x}\right)^{2}\right)$

$\mathbf{G}_{\boldsymbol{b}}$ kinetic energy generation by buoyancy

$\mathrm{G}_{b}=\frac{\mu_{t}}{\sigma_{t}} \frac{\partial T}{\partial y} g \beta$

Where " $\mathrm{C}_{\mu}$ " is the value of an empirical constant for a flow with a large Reynolds number. The working fluid is air, which has a prandtl number of (0.7) and produces a uniform heat flux on the absorber wall.

Table 1: Values of constants in the $(\mathrm{K}-\boldsymbol{E}) \operatorname{models}[19]$

\begin{tabular}{|c|c|c|c|c|c|}
\hline $\mathbf{C}_{\boldsymbol{\mu}}$ & $\mathbf{C}_{\mathbf{1}}$ & $\mathbf{C}_{\mathbf{2}}$ & $\mathbf{C}_{\mathbf{3}}$ & $\boldsymbol{\sigma}_{\varepsilon}$ & $\boldsymbol{\sigma}_{\boldsymbol{k}}$ \\
\hline 0.09 & 1.44 & 192 & 1.0 & 1.3 & 1.0 \\
\hline
\end{tabular}

\section{RESULTS AND DISCUSSION}


In the study of the air gap $(0.1,0.2) \mathrm{m}$ between the absorbing surface and the glass, with inward inclination angle $\left(0^{\circ}, 5^{\circ}, 10^{\circ}\right.$ and $\left.15^{\circ}\right)$ and that calculation will depend on the radiation intensity from $(150,250,350,450,550,700) \pm 10\left(\mathrm{~W} / \mathrm{m}^{2}\right)$ to ensure that the same results are obtained on any day from any month in the year and the results displayed based on the May 2021.

\subsection{Air change per hour ( $\mathrm{ACH})$}

The air volume supplied to or withdrawn from a space in one hour, divided by the volume of the space, is measured in air changes per hour, abbreviated ACPH or ACH [18]. Air changes per hour is a measurement of how many times the air inside a specified area is changed each hour if the air in the space is either uniform or completely mixed. This index can be determined using the ASHRAE equation (5)[18]. the velocity at inlet of the test model and inlet of the chimney was measured at several locations. Then the air volume flow rate was evaluated according to equation-(6). The calculate $\mathrm{ACH}$ for the all absorber plate are used in experimental work model as show in Figure 6 the flat absorber plate with air gap $0.1 \mathrm{~m}$ and different inclination angle. The best angle is $0^{\circ}$ to improved maximum ACH in the practical model (4.8) at $700 \mathrm{~W} / \mathrm{m} 2 \pm 10$. Figure 7 represent absorber flat plate with air gap $0.2 \mathrm{~m}$ with deferent angle inclination inward the ACH in this case at $700(\mathrm{~W} / \mathrm{m} 2) \pm(10)$ the optimum angle is $0^{\circ}$ and the change per hour is 8.8. ACH the flat plate at $0^{\circ}$ angle of inclination with $0.2 \mathrm{~m}$ air gap is more by $83 \%$ than $0.1 \mathrm{~m}$ air gap.

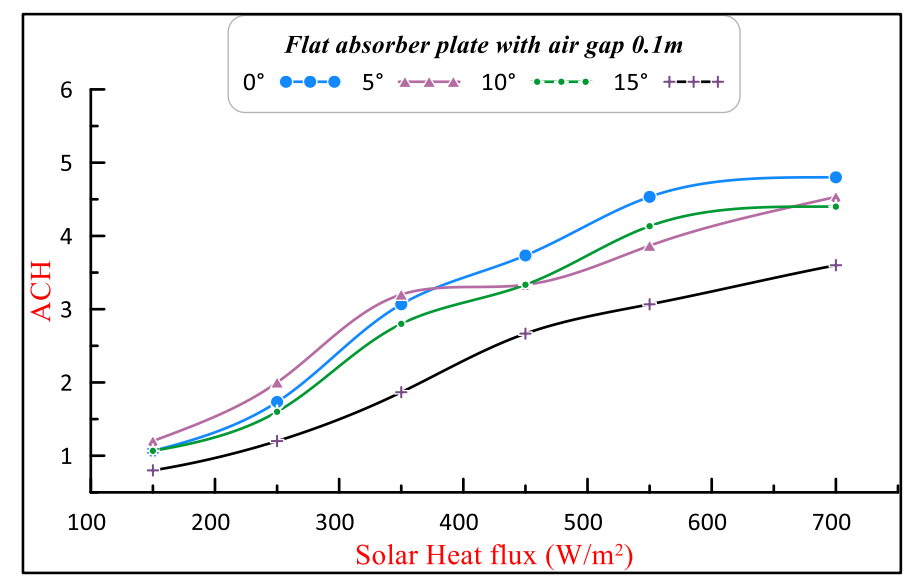

Figure 6. Air Change per hour with solar heat flux of flat absorber plate with air gap 0.1 and different angle of inclination.

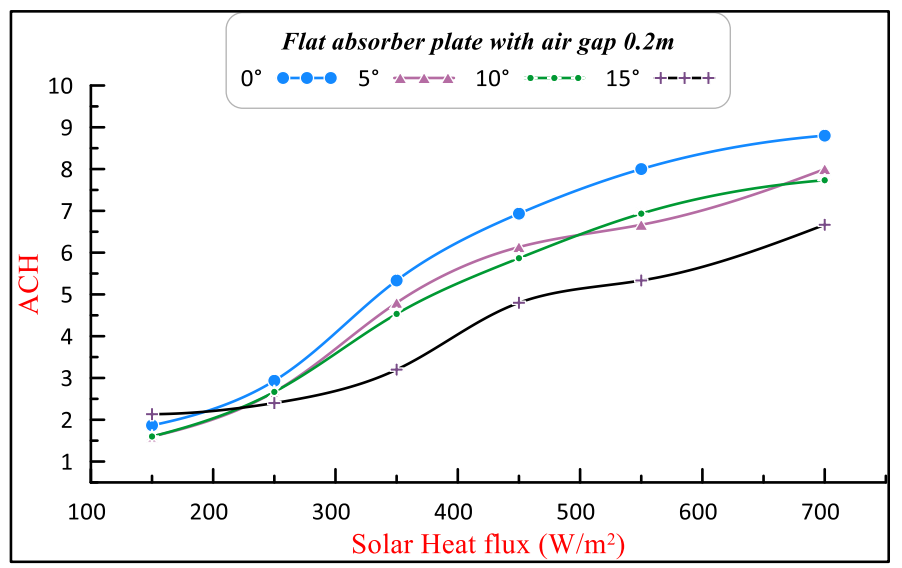

Figure 7. Air Change per hour with solar heat flux of flat absorber plate with air gap 0.2 and different angle of inclination.

Figure 8 represented the $\mathrm{ACH}$ with solar intensity of triangular $\mathrm{V}$-grooved absorber plate with air gap 0.1.the optimum angle for the situation is $10^{\circ}$ at heat flux $700 \mathrm{~W} / \mathrm{m} 2 \pm 10$ about $6 \mathrm{ACH}$. 
Figure 9 Show that the same absorber plate above and similar case but air gap $0.2 \mathrm{~m}$ denoted the increased $\mathrm{ACH}$ with increasing outlet area the $\mathrm{ACH}$ reach to maximum value to 9.6 at heat flux 700 $(\mathrm{W} / \mathrm{m} 2) \pm(10)$ at optimum angle $10^{\circ}$ tilt inward of experimental model the ratio of increasing percentage for this case is $60 \%$ batter than $0.1 \mathrm{~m}$ air gap. and the absorber flat plate with $0.2 \mathrm{~m}$ air gap by $9 \%$

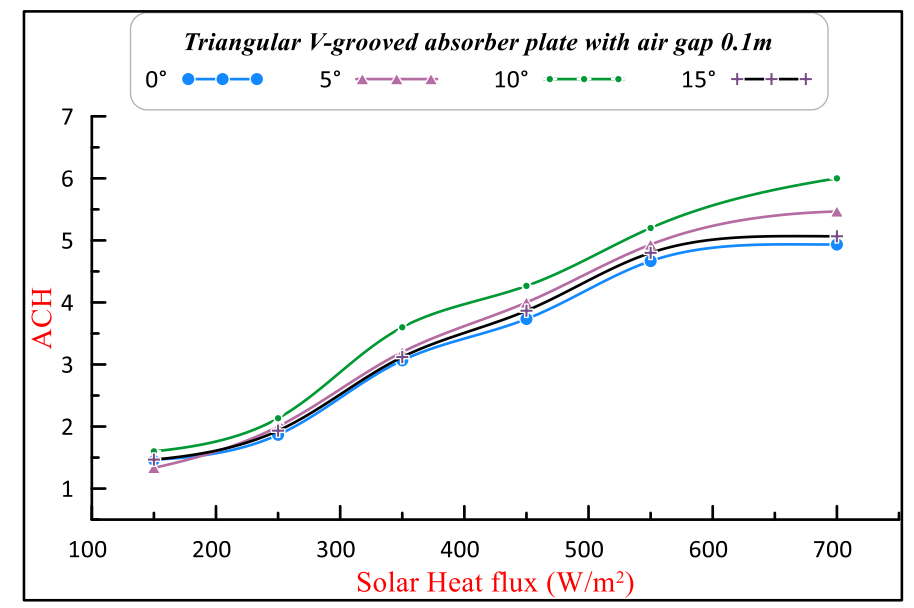

Figure 8. Air Change per hour with solar heat flux of V-grooved absorber plate with air gap 0.1 and different angle of inclination

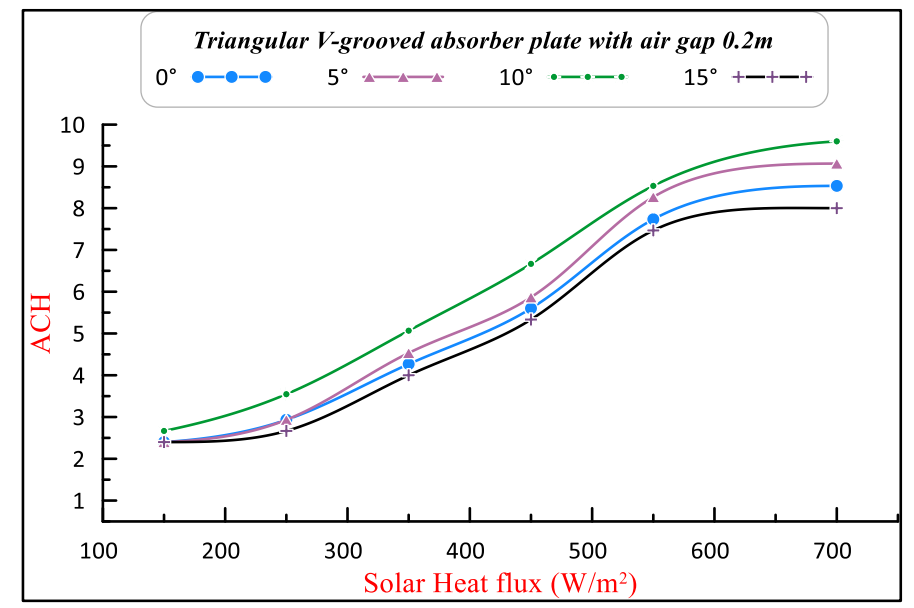

Figure 9. Air Change per hour with solar heat flux of V-grooved absorber plate with air gap 0.2 and different angle of inclination.

Figure 10 represented the trapezoidal corrugated absorber plate with air gap $0.1 \mathrm{~m}$ and different inclination angle. Show that the maximum $\mathrm{ACH}$ at approximately 4.5 with tilt angle $0^{\circ}$ at heat flux $700(\mathrm{~W} / \mathrm{m} 2) \pm(10)$.

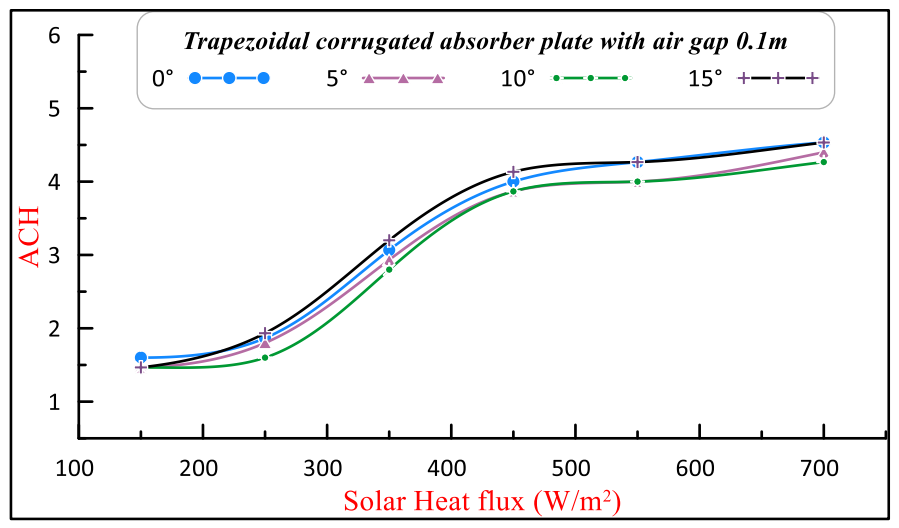


Figure 10. Air Change per hour with solar heat flux of Trapezoidal absorber plate with air gap 0.1 and different angle of inclination.

Figure 11 represented the same case above but with air gap $0.2 \mathrm{~m}$.the $\mathrm{ACH}$ is increased with increasing outlet area the maximum $\mathrm{ACH}$ at $\left(5^{\circ}, 10^{\circ}\right)$ is about 8.2 the tilt inward at their angle make the turbulent of air due to the density of air become lower, although of the explanation but it still not effective than flat and $\mathrm{V}$-grooved absorber plate due to the shadow between ribs the absorber flat plate at $0.2 \mathrm{~m}$ with $0^{\circ} \mathrm{ACH}$ reading is more the trapezoidal corrugated plate with $0.2 \mathrm{~m}$ at $\left(5^{\circ}, 10^{\circ}\right)$ about $7.3 \%$.and the $\mathrm{V}$-grooved is better than about $16.2 \%$.

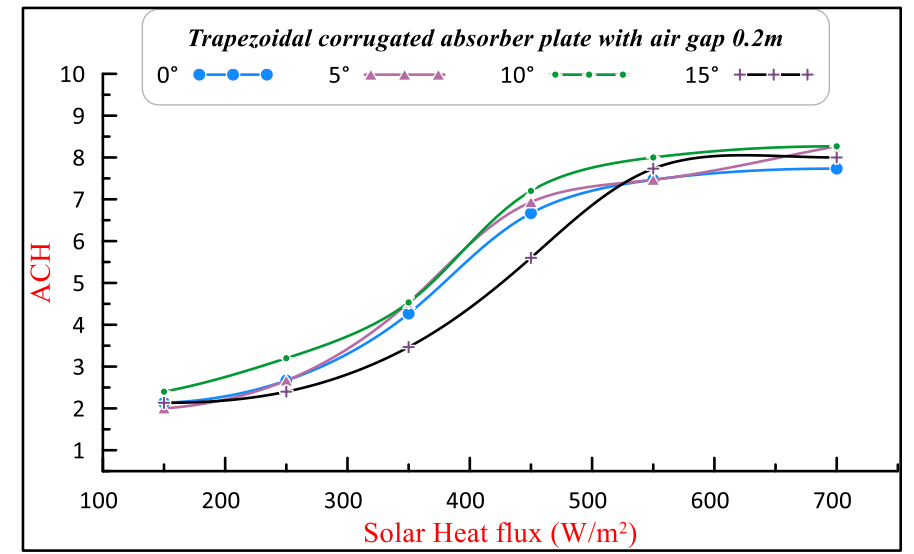

Figure 11. Air Change per hour with solar heat flux of Trapezoidal absorber plate with air gap 0.2 and different angle of inclination.

From the experimental and numerical result of flat absorber plate with air gap 0.1 and $0.2 \mathrm{~m}$ show the optimum angle is $0^{\circ}$. And in case of triangular $\mathrm{V}$-grooved absorber plate the best angle of inclination is $10^{\circ}$ in experimental investigation at air gap $(0.1,0.2) \mathrm{m}$. The trapezoidal absorber plate in the field of practical tests, it was found that the best angle of inclination is $0^{\circ}$ and very small effect of inclination angle $\left(5^{\circ}\right.$ and $\left.10^{\circ}\right)$ and this effect neglect and take angle $0^{\circ}$ is the best.

Figure 12 show the compare for ACH of three absorber plate type at best angle of inclination for each one with solar heat flux and air gap width $(0.1,0.2) \mathrm{m}$.

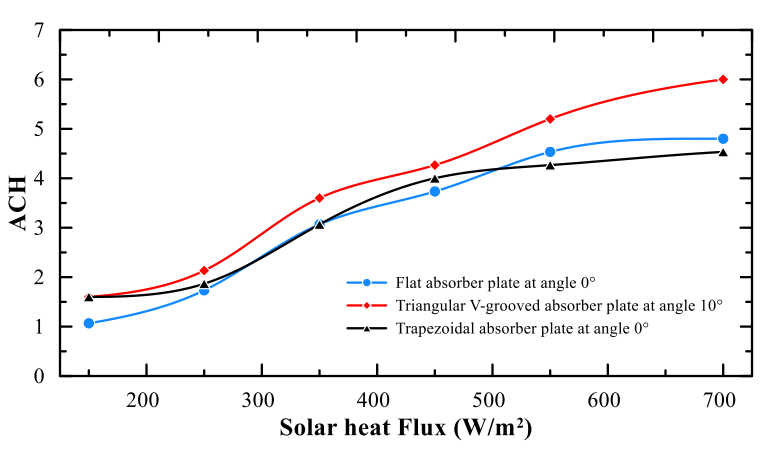

(a) $0.1 \mathrm{~m}$ Air gap width

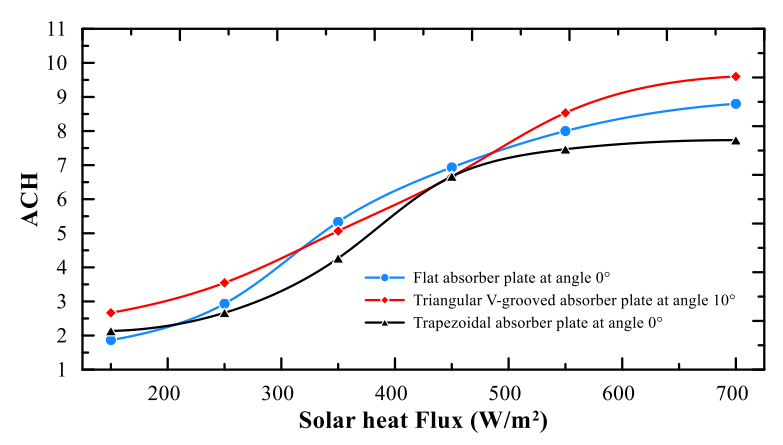

(b) $0.2 \mathrm{~m}$ Air gap width

Figure 12. Air Change per hour with solar heat flux of optimum inclination angle for absorber plates with air gap width (a) $0.1 \mathrm{~m}$ and (b) 0.2

\subsection{Numerical and experimental validation}

Figure 13, Figure 14 and Figure 15 show Comparison between Numerical and Experimental results for variation of exit velocity with solar heat flux for absorber plate (flat, V-grooved and trapezoidal) respectively at the optimum angle for each one. It can be observed that both experimental and 
numerical results have the same behavior. It is found that the predicted results are greater than the experimental results, the difference was about $11 \%$ for flat plate and the deviation between the numerical and experimental of $\mathrm{V}$-grooved absorber case about $14 \%$ that show good agreement between the result. Also 17\% for trapezoidal plate. This difference can be attributed to the following reasons:

* Ignoring the heat lost by radiation from the outside glass cover surface of the solar chimney to the atmosphere.

* Ignoring the radiation heat transfer between the absorber plate and glass cover.

The length of absorber flat plate is $0.9 \mathrm{~m}$ and the V-grooved plate is $1.24 \mathrm{~m}$ and the trapezoidal is $1.52 \mathrm{~m}$ the last two plates is corrugated to the charistraic length $0.9 \mathrm{~m}$. The trapezoidal plate is larger than flat plate by $68 \%$ and V-grooved by $22.5 \%$ bet it is not the best absorber plate. The ribs of the absorbing surface form the shade, the area exposed to the sun's rays gets hotter, and the area that the sun's rays do not reach is colder by a difference of $10-8{ }^{\circ} \mathrm{C}$, and the heat gained in the shade is the result of conduction from the exposed surface Solar radiation has this difference significantly on the performance of this type, which is considered the worst test model, meaning that the flat surface better than trapezoidal surface and V-grooved better of them. When inclined inward as a result of the refractions of sunlight and the little heat between the ridges, the air density and the value of the flow decrease as a result of the fact that the rims are obstructed without sufficient heat, which makes it unacceptable in terms of practical use of the large surface area.
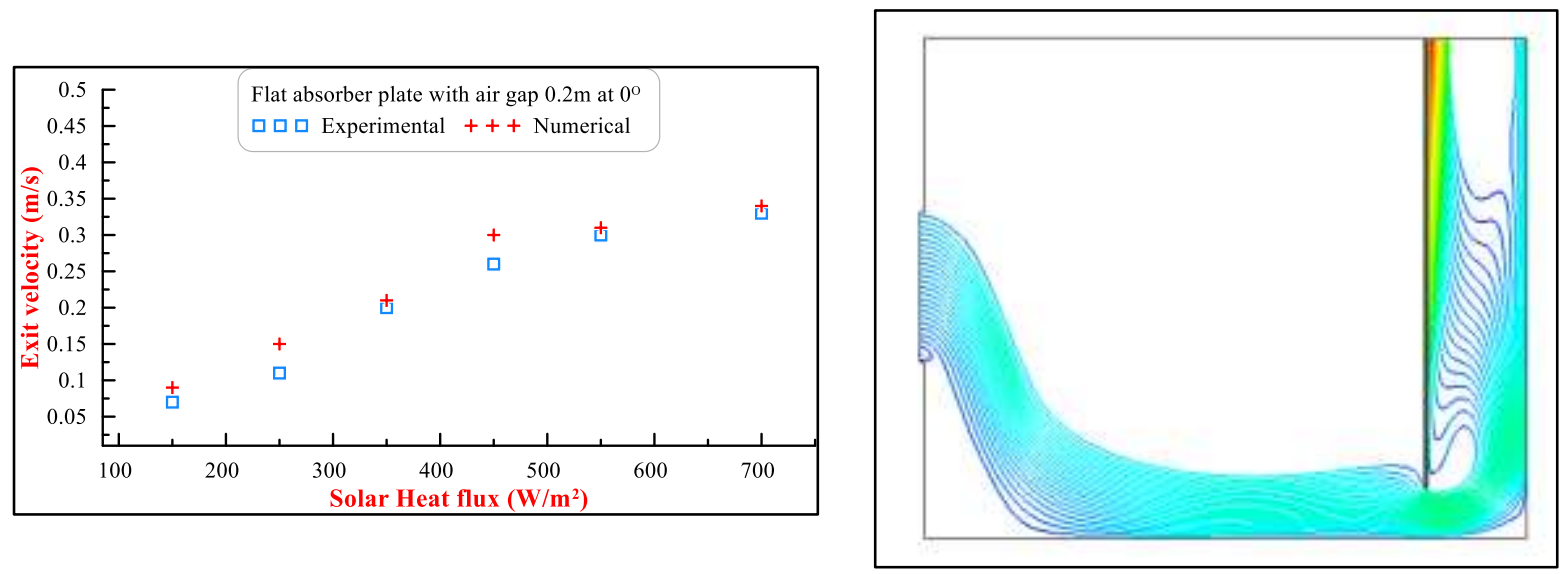

Figure 13. Comparison between Numerical and Experimental results for variation of exit velocity with solar heat flux for absorber flat plate at air gap $0.2 \mathrm{~m}$ and inclination angle $0^{\circ}$.
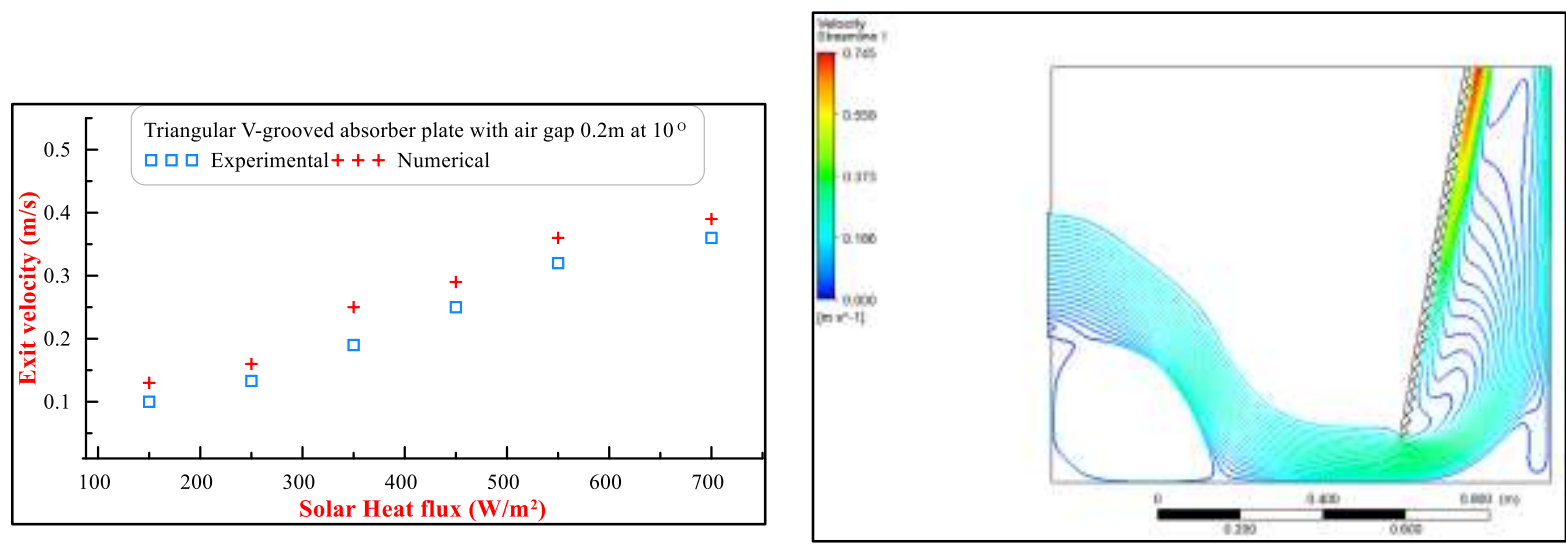
Figure 14. Comparison between Numerical and Experimental results for variation of exit velocity with solar heat flux for absorber $V$-grooved at air gap $0.2 \mathrm{~m}$ and inclination angle $10^{\circ}$

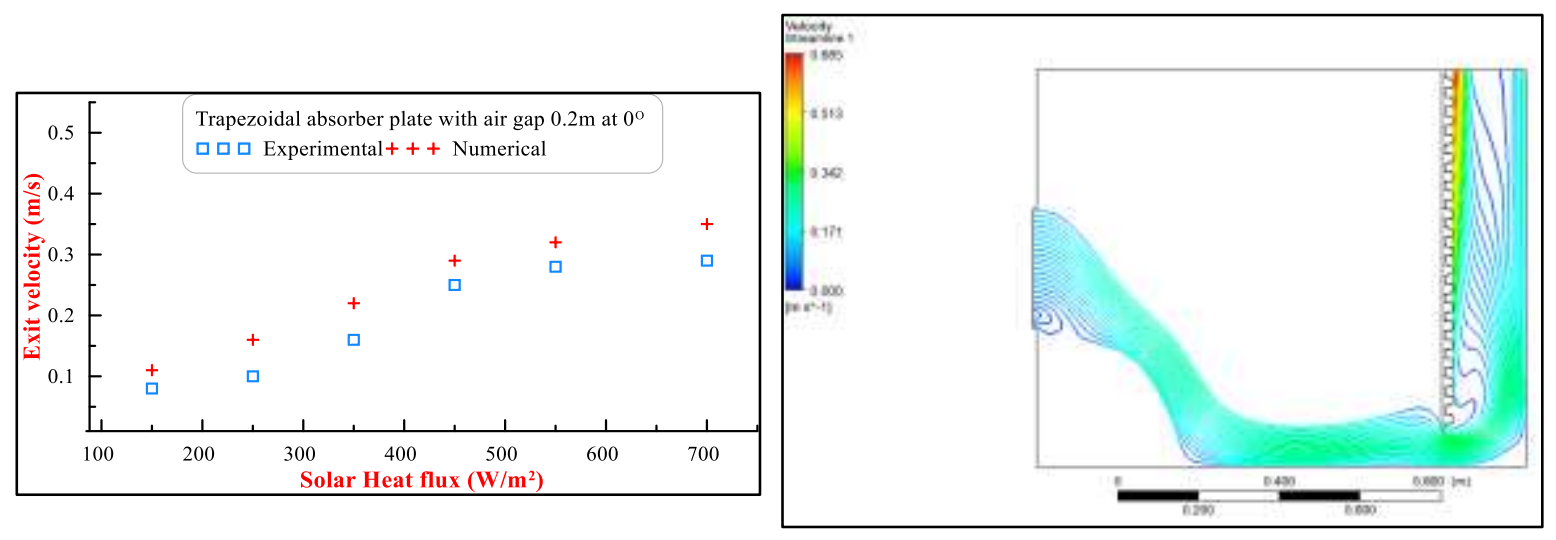

Figure 15. Comparison between Numerical and Experimental results for variation of exit velocity with solar heat flux for Trapezoidal absorber plate at air gap $0.2 \mathrm{~m}$ and inclination angle $0^{\circ}$

\subsection{Validation Results with previous literature}

The results of the test case are presented in Figure 16. This figure show a comparison between the present numerical and experimental with the results of numerical result Bhardwaj[5] and experimental and numerical result Mathur[8] and theoretical result of Bassiouny and Koura [10] all this studies above do the theoretical and experimental on the flat absorber plate and present study validate with previous work but with the triangular $\mathrm{V}$-grooved absorber plate at $0^{\circ}$ angle of inclination. the Table 2 explain the result of previous work and present theoretical and experimental work the area of this absorber is more the above by $39 \%$.

Table 2 Validation with important previous study

\begin{tabular}{|c|c|c|c|c|c|c|c|}
\hline \multicolumn{7}{|c|}{ Air change per hour } \\
\hline $\begin{array}{c}\text { Heat } \\
\text { flux } \\
\left(\mathrm{W} / \mathrm{m}^{2}\right)\end{array}$ & $\begin{array}{c}\text { Air } \\
\text { Gap } \\
(\mathrm{m})\end{array}$ & $\begin{array}{c}\text { Theo. } \\
(\text { Bhardwaj[5] }\end{array}$ & $\begin{array}{c}\text { Exp.Study } \\
\text { (Mathur } \\
\text { et al.[8] })\end{array}$ & $\begin{array}{c}\text { Theo.Study } \\
\text { (Mathur et } \\
\text { al.[8]) }\end{array}$ & $\begin{array}{c}\text { Theo. } \\
\text { (Bassiouny } \\
\text { and } \\
\text { Koura[10] }\end{array}$ & $\begin{array}{c}\text { Exp. } \\
\text { Present } \\
\text { study }\end{array}$ & $\begin{array}{c}\text { Theo. } \\
\text { Present } \\
\text { study }\end{array}$ \\
\hline $\begin{array}{c}250- \\
300\end{array}$ & 0.1 & 2.217 & 2 & 2.497 & 2.249 & 2.466 & 2.573 \\
\hline $\begin{array}{c}450- \\
500\end{array}$ & 0.1 & 2.816 & 2.4 & 2.992 & 2.739 & 3.89 & 4.11 \\
\hline 700 & 0.1 & 3.253 & 2.662 & 3.125 & 3.118 & 4.9 & 5.06 \\
\hline
\end{tabular}

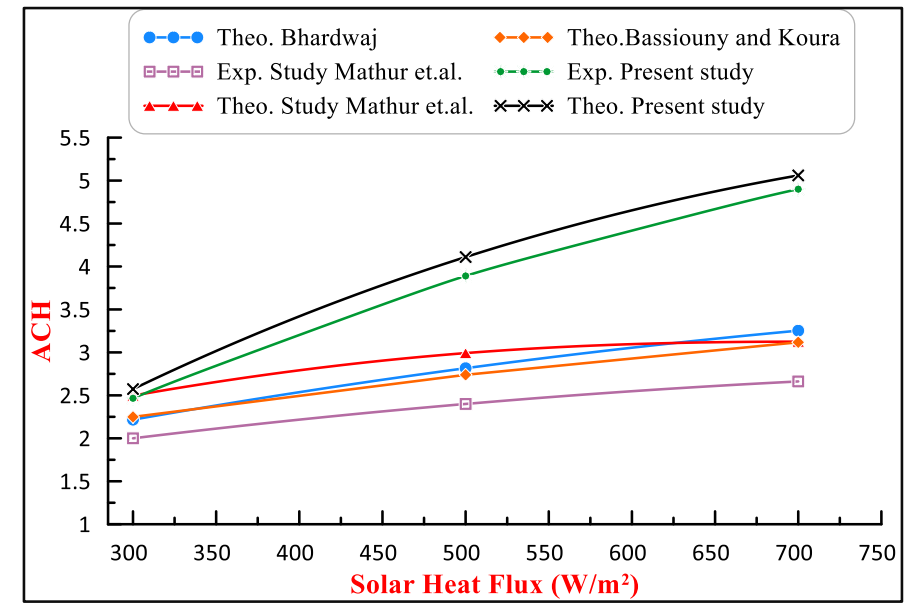


Figure 16. validation present work with previous study

\section{CONCLUSION}

Heat transfer from the absorber wall to the air inside the chimney channel, chimney outlet cross section area, solar radiation and absorber plate type are all important factors that contribute to the growth of the buoyancy force and increased the turbulence within the solar chimney channel, which then leads to induced air movement in the room space. The highest deviation between the practical and the theoretical side of room temperature is between (2-3) ${ }^{\circ} \mathrm{C}$ From all cases, it can be concluded that the numerical results showed similar behavior to the experimental results. the experimental results had slightly lower values than numerical results, and this can be attributed to the assumptions of the numerical simulation, ignoring radiation heat transfer in the numerical model. The comparison between the experimental and numerical results for exit velocity from the solar chimney channel is about $14 \%$ for all cases This difference can be attributed to the reasons of ignoring the heat lost by radiation from the outside glass cover surface of the solar chimney to the atmosphere and ignoring the radiation heat transfer between the absorber plate and glass cover. Experimental and theoretical results of the present study show that the optimum models of the test absorber plate with air gap width and inclination angle according to Air change per hour (ACH) calculation is model2 (triangular Vgrooved absorber plate) with $0.2 \mathrm{~m}$ air gap width at $10^{\circ}$ angle of inclination. At this inclination angle and air gap width the $\mathrm{ACH}$ is about $10 \%$ higher than modell (flat absorber plate) and more than model 3 by $17 \%$.

\section{RECOMMENDATIONS}

In future research, there is a need for further study on this subject and some investigations which could be carried out are given below:

- For more accurate of experimental result, conducting experiments on the same test model but in a room completely isolated from the influence of the outside condition effect and only the solar chimney outside the room.

- Study the effect of corrugated absorber with other shape and dimension at outward inclination angle $\left(90^{\circ}, 60^{\circ}, 45^{\circ}\right.$ and $\left.30^{\circ}\right)$.

\section{REFERENCE}

[1] Y. Zhou, G. E. Jing, X. H. Liu, and Q. L. Li, "Research for ventilation properties of solar chimney with vertical collector." 2011.

[2] M. Maerefat and A. P. Haghighi, "Passive cooling of buildings by using integrated earth to air heat exchanger and solar chimney," Renew. Energy, 2010.

[3] Admn, "BUREAU OF INDIANA STANDARDS." 2012.

[4] R. Khanal and C. Lei, "A numerical investigation of buoyancy induced turbulent air flow in an inclined passive wall solar chimney for natural ventilation." 2015.

[5] M. Bhardwaj and G. D. Agrawal, "Optimization of solar chimney for ventilation in buildings using Taguchi method," 2018.

[6] M. H. Naraghi, "Twenty-four hour simulation of solar chimneys.” 2015.

[7] M. A. Karim and M. N. A. Hawlader, "Development of solar air collectors for drying applications." 2004.

[8] J. Mathur, "Experimental investigations on solar chimney for room ventilation." 2006. 
[9] R. Khanal, "An experimental investigation of an inclined passive wall solar chimney for natural ventilation Rakesh." 2014.

[10] R. Bassiouny and N. S. A. Koura, "An analytical and numerical study of solar chimney use for room natural ventilation.” 2008.

[11] Ahmed A. Imran, "Induced flow for ventilation and cooling by a solar chimney." 2015.

[12] A. Abdeen, A. A. Serageldin, M. G. E. Ibrahim, A. El-Zafarany, S. Ookawara, and R. Murata, "Solar chimney optimization for enhancing thermal comfort in Egypt: An experimental and numerical study." 2019.

[13] N. K. Bansal, J. Mathur, S. Mathur, and M. Jain, "Modeling of window-sized solar chimneys for ventilation," 2005.

[14] H. B. Awbi, "Ventilation of Buildings." 2005.

[15] Maiti and Bidinger, "Holman Heat transfer," J. Chem. Inf. Model., 1981.

[16] D. Yang and Y. Guo, "International Journal of Heat and Mass Transfer Fluctuation of natural ventilation induced by nonlinear coupling between buoyancy and thermal mass." Elsevier Ltd, 2016.

[17] R. T. Sataloff, M. M. Johns, and K. M. Kost, Heat and Mass Transfer 7th. 2007.

[18] R. H. Howell, "Principles of Heating Ventilating and Air Contitioning, 7th Edition," Ashrae. 2013.

[19] D. D. Gray and A. Giorcini, "OF THE BOUSSINESQ APPROXIMATION FOR LIQUIDS AND GASES," 1976. 